\title{
The Text Type Effect on Moroccan EFL University Learners' Reading Achievement
}

\author{
Mohammed Msaddek ${ }^{1}$ \\ ${ }^{1}$ Regional Academy for Education and Training (Rabat- Salé), Delegation of Salé, Morocco \\ Correspondence: Mohammed Msaddek, BP 5932, Casa Takadoum, C.P: 20351, Casablanca, Morocco. Tel: \\ 212-642-630-991. E-mail: msadek60@gmail.com
}

Received: May 1, 2017 Accepted: May 26, 2017 Online Published: May 30, 2017

doi:10.5539/ells.v7n2p99 URL: http://doi.org/10.5539/ells.v7n2p99

\begin{abstract}
This study is a potential endeavor to make an inquiry into the perceived effect of text typology on reading achievement gains among Moroccan English as a foreign language (EFL) learners. It also evinces whether strategy instruction can be an influencing variable on learners' reading achievement with regards to text type (i.e., narrative, expository). Indeed, incorporating two primary text genres (i.e., narrative, expository) in the conduct of this current research, the study is intended to substantiate any marked interrelatedness existing between text typology and reading achievement at the pre- and post-testing stages among EFL university learners. For assuring a thorough, rich investigation of this stated postulate, two sampled Moroccan EFL groups $(\mathrm{n}=113)$, as first-year English majors, were addressed. The obtained data were collected by means of a corpus of research instruments such as reading comprehension tests (i.e., pre-test, post-test), strategy training and reading comprehension texts (i.e., narrative, expository). The findings showcased that text genre is not a significant, influential variable on reading achievement scores among the control $(n=50)$ and treatment groups $(n=63)$. Finally, the study puts forward some useful implications pertaining to EFL text processing/ analysis and an explicit mention of some limitations, which encountered the undertaken study, is made.
\end{abstract}

Keywords: reading comprehension, text processing, narrative text, expository text, strategic behavior

\section{Introduction}

Assuming the stark complexity of conducting academic English as a foreign language (EFL) reading at the university level, it is apparent that text processing and analysis, as a cognitive enterprise in the field of academia, entails "high-level" thinking processes (e.g., Rapp \& van den Broek, 2005) and flexible strategy usage on the part of EFL learners for comprehension achievement purposes. This plainly unveils that learners do engage in the synthesizing process and resort to diverse text-based strategies with a view to making meaningful sense of the textual content regardless of which typology of the discourse that they tend to cope with. In other words, though text type at times dictates more frequent use of some reading strategies than others (Baritta et al., 2009; Yoshida, 2012), the attainment of sufficient, efficient understanding of the written input remains the ultimate goal of any undertaken reading act among EFL learners. This is basically underscored by Smith (1982) who argues that reading certainly implies comprehension.

Also, much outstanding research on the process of EFL text reading has been done from the schema-theoretic (e.g., Johnson, 1982; Carrell, 1984), interactive (Anderson \& Pearson, 1988), meta-cognitive (Mokhtari, \& Sheory, 2002; Iwai, 2016) and strategic (Casanave, 1988; Mothtari \& Reichard, 2002; He, 2008) perspectives. This exceedingly rich, extensive research has shown the basal specifics and major intricacies governing the sense-making procedure in the reading behavior among EFL learners. Also, tackling the influence of text genre (i.e., narrative, expository) on strategic reading processes has been the primary focus of a group of reading specialists and researchers (e.g., Afflerbach, 1990; Best et al., 2008; Yoshida, 2012). This has shed light on the interdependency and "interactivity" between the variable of strategy use and the variable of text typology. Yet, further and extended research, couched within the confines of EFL reading as a basic receptive skill in any academic context, is needed to provide more illustrative, relevant and confirmatory findings that contribute to both the enrichment of EFL reading comprehension research and the plausible understanding of the academic EFL reading act as regards text type, namely narrative and expository.

In effect, given the constant and frequent exposure of most EFL learners to written discourse of narrative and 
expository type in their academic studies, many reading researchers have opted for investigating the reading process by including these two typologies of texts in their studies (i.e., Best et al., 2008; Baretta et al., 2009; Yoshida, 2012). However, most relevant literature on reading research has tended to manifest the plain influence of text genre on learners' reading processes/ strategies and thinking mechanisms during text analysis and meaning synthesis and neglected the text type impact on learners' reading achievement scores. Thus, the gap existing in the current reading research is apparent in the lack of delving deeply into the extent to which the underlying factor of text type (narrative \& expository) can influence learners' reading performance gains. It is this posited perspective on which the present research tends to put a bright spotlight with the focal aim of confirming whether EFL learners' reading achievement is genre-dependent or remote from "genre-sensitivity".

\section{Theoretical Framework}

\subsection{Reading Comprehension}

Reading comprehension, by definition, is the process via which the reader intends to identify the meaning included in the written text. It is "the internal thinking during which meaning is constructed through interactions between text and reader" (Harris \& Hodges, 1995). In fact, accessing and making complete sense of the content of a particularly given textual input is a clear indication of the achievement of an adequate comprehension. In this regard, the concept of reading comprehension, as maintained by Smith (1982), can be referred to as "meaning identification". That is, in attempting to read the text, learners focus on the intended meaning which "is always relative to what they know and to what they want to know" (Smith, 1982). On the basis of this principle, it is assumed that the two concepts, the reading process and the textual comprehension, are intimately intertwined.

Furthermore, Snow (2002) notes that reading comprehension consists of three componential elements: the reader, the text, and the activity or purpose for reading. This demonstrates that the learner plays an active role in attempting to make sense of the meaning of the text by drawing upon various effectual reading strategies (e.g., inferring, monitoring, questioning). In addition, the content of text, if it is properly processed and analyzed, can also assist the learners to attain fuller comprehension, i.e. reading comprehension, as a purely cognitive process, is the outcome of the interaction between the reader's previously acquired knowledge and the content of the written input. Of equal, fundamental importance is the setting of purpose before being engaged in the task of textual interpretation. It is considered another precondition to achieving an effective understanding. In effect, "the reader processes the text with regard to the purpose" (Snow, 2002). Given that reading comprehension is based on these three variables (e.g., the reader, the text, the reading rationale), it plainly implies the analysis, synthesis and interpretation of the ideas and conceptualizations reflected in the written input.

It can be claimed that an effective comprehension of the written texts is highly dependent on the use of some specific reading strategies that are of substantive importance and greater help to the meaning construction task. Obviously, in addition to the possession of wider, richer knowledge of lexical items which facilitates the processing of the text in an efficient manner, the comprehension process also requires a sophisticated kind of critical thinking on the part of student-readers in order to understand the content of the given discourse more elaborately and perfectly.

\subsection{Schema-Theoretic Approach}

Based on the clear-cut view of the interactive approach that reading essentially involves the interaction between the reader and the text, the schema-theoretic approach tends to emphasize a similar perspective and gives higher importance to the prime role of background knowledge in text processing. It conceives of reading as an interactive process in which readers count on both bottom-up (data-driven) processing and top-down (conceptually-driven) processing (Carrell, 1984). This, indeed, alludes to the fact that the process of comprehending the written text (i.e., narrative, expository) mainly consists in the readers' prior knowledge, predictions and expectations. So, within the general framework of the schema theory, it is assumed that an efficient textual comprehension can only be attained via activating an appropriate, relevant schema that provides readers with the necessary knowledge and pertinent thoughts for interpreting the target content.

According to Rumelhart (1984), a schema theory is "a theory about how knowledge is represented and about how that representation facilitates the use of knowledge in particular ways". This evidently reflects that the readers' schemata encompass broad knowledge about basic ideologies that enable the processing, analysis and interpretation of the information included in the written discourse. This can only be achieved by readers if they activate the proper schemata to which they are expected to bring what is stated in the printed text. Hence, considering that schemata are the foundational basis for the overall achievement of content comprehension, it is plain that they have a key role in the reading process. In this context, Anderson (1978) and Anderson \& Pichert 
(1978) affirm that the schemata have six primary functions which are:

(1) to provide ideational scaffolding for assimilating the target text.

(2) to facilitate selective allocation of attention.

(3) to enable inferential elaboration.

(4) to allow orderly searches of memory.

(5) to facilitate editing and summarizing.

(6) to permit inferential reconstruction.

Importantly, many researchers (e.g., Alderson, 2000; Carrell, 1987) recognize two broader types of schemata: content schemata and formal schemata. The first type refers to the readers' existing knowledge of the subject matter of the text. It constitutes an essential precondition to undertaking an efficient reading and achieving understanding. In fact, the familiarity with the text content results in an enhanced reading performance (Alderson \& Urquhart, 1988). Moreover, this type of schemata also includes the cultural knowledge which is deemed of critical significance in enabling the learners to approach a given text more effectively and properly. The fact of knowing some cultural ideologies and particularities provides readers with an insight into the textual message that is intended by the author/writer.

As regards the second type, the formal schemata, it denotes the readers' knowledge about the organization and structure of certain typologies of written texts (i.e., narrative, expository). For instance, in reading literary or narrative texts (e.g., short stories, novels), student-readers invariably expect that there exist the setting, characters, themes and events, whereas in coping with expository texts, readers presuppose that they are to explore basic facts, crucial ideologies and underlying conceptualizations about certain issues. This distinction between the nature and types of the textual discourse enables the learner, in a way, to invoke the fitting strategic steps for analyzing the content. Thus, a facilitative effect of this type of schemata on text reading and meaning identification is apparent.

In light of what has been said, it is worth reiterating, then, that the schema-theoretic approach places a focal emphasis on the actual interaction between the readers' previously acquired knowledge and the textual information. The activating of a fitting schema while being engaged in reading the text content allows readers to elaborate on the contained meaning, and thus attain an effective comprehension. Realistically, the background or schematic knowledge of the reader substantially contributes to the process of meaning-building in differing ways (Carrell, 1984).

\subsection{Interaction between Text Type \& Reading Process}

The variable of text genre is a crucial element which typically characterizes the written texts of diverse sorts. It primarily serves as a "frame of reference" directing readers to analyze and interpret the textual content in a convenient, efficient manner. In actuality, granted that EFL learners are invariably exposed to a wide plethora of printed texts in the course of their academic studies, it is assumed that text type can impact the learners' mode of reading behaviour. In other terms, the strategy selection and utilization can be directed, to some extent, by the genre of the written text being studied and read. In this sense, text genre is viewed by Pappas \& Pettegrew (1998) as a critical feature in the reading skill. Simply put, reading, as a process involving the recruitment of many strategic moves, is correlated with the genre since the latter embodies the nature of the given text from a linguistic and content perspective.

Indeed, many researchers have come to the manifest realization that narrative passages differ from expository ones at the content level on a large scale. This is sturdily emphasized by Yoshida (2012) who argues that important differences do exist in structure and content between narrative and expository texts. Further, other researchers (e.g., Best et al., 2008) maintain that narrative texts follow a simple structure and a sequence of causally related events. Thus, learners tend to process the content of the narrative discourse more readily and effectively. On the other hand, expository passages put "increased processing demands on the reader due to their greater structural complexity, greater information density, and greater knowledge demands" (Best et al., 2008). In actual fact, tending to process expository texts, learners preconceive that these texts include some crucial facts and ideologies about certain issues and phenomena the perception of which entails critical thinking and reasoning skills. This evinces that making sense of narrative passages is easier than processing written texts of expository type (Best et al., 2008; Yoshida, 2012).

The prime difference as regards text content processing is embodied in the heavy dependence of some strategic processes for the attainment of adequate comprehension of the writer's/ author's views and conceptualizations. 
In effect, during textual synthesis, some of the strategies used by the EFL learners slightly differ according to the kind of the written text being processed (i.e., narrative, expository). This slight variability concerning the strategy deployment is governed by the typology of the written discourse which presupposes effective strategic processes that are certain to facilitate the reading comprehension task among EFL readers. For instance, narrative texts entail the extensive usage of visualizing for easing the act of understanding the events, actions, characters' behaviours and themes. Contrastingly, expository texts require the use of multiple strategies (e.g., rereading, synthesizing, paraphrasing, prior knowledge) in order to reach a coherent grasp of the textual content. This reveals that expository texts present a wide range of difficulties for learners at the level of comprehension construction (Zhou \& Siriyothin, 2011). Yet, Taking into account that strategy use is, to an extent, genre-specific, the present study tends to highlight the impact of text type (i.e., narrative, expository) on EFL learners' reading achievement gains.

\section{Research Objectives \& Research Questions}

The current study is intended for the exploration of the likely effect of text type on reading achievement gains among Moroccan EFL first-semester university learners. It seeks to show the impact of text typology on EFL learners' reading test scores at the pre- and post-testing levels. For obtaining pertinent and relevant data, the usage of some research instruments was resorted to in an endeavour to realize the prime objective that undergirds the empirical framework of this conducted research. The research-based tools include the reading comprehension texts (i.e., narrative, expository) and reading pre- and post-tests (narrative \& expository). Therefore, two major research questions, gearing the present research towards the attainment of some useful implications and conclusions, have been formulated.

a. To what extent are the Moroccan EFL university learners' reading achievement gains genre-dependent?

b. To what extent does reading strategy instruction impact Moroccan EFL university learners' achievement gains on narrative and expository reading tests?

\section{Research Hypotheses}

Based on the above-cited research questions, two major research hypotheses have been formulated in the light of the relevant literature on the issue. These hypotheses, intended to thoroughly investigate the current study under scrutiny, are put forward as follows:

a. Text type does not have an impact on Moroccan EFL university students' reading achievement gains.

b. Strategy instruction cannot be an influencing element on learners' reading achievement gains with regards to text type (i.e., narrative, expository).

\section{Method}

\subsection{Participants}

The current study targets one hundred and thirteen Moroccan EFL university students belonging to the English language department at the Faculty of Letters and Human Sciences, Mohammed V- Agdal in Rabat. The EFL participants undertake their English Studies at the first-semester level. Two EFL groups were randomly selected among multiple EFL groups by the researcher and each group is made up of mixed-ability learners. One group $(n=63)$ served as the experimental group, whereas the other group $(n=50)$ was assigned to the control condition. The subjects belonging to these two groups (i.e., control, experimental) are not repeaters and they have a similar educational background. The chief rationale behind the mere selection of two groups is to draw a comparison between the treatment and control groups as to reading scores at pre- and post-test levels. This will further highlight whether text type is a strong predictor of EFL learners' reading achievement.

\subsection{Procedure}

This exploratory study is firmly founded on a pre-post-test design involving a reading pre-test (narrative \& expository) and a reading post-test (narrative \& expository). These reading tests were administered to the control and experimental groups. After being pre-tested, the treatment group $(\mathrm{n}=63)$ received a comprehensive instruction in strategy use in an attempt to reinforce their strategic awareness for a semester-long period (Fall Term/ 2012). This procedure was effected through the delivery of a large corpus of written discourse (i.e., narrative, expository) along the intervention course. By contrast, the control group $(n=50)$, not being exposed to any systematic training in strategy knowledge and usage, was taught the reading comprehension in the traditional manner. Indeed, the same pre-test (narrative \& expository), which was accorded to the treatment group, was assigned to the control group. At the end of the semester, both the experimental group and controls were post-tested on narrative and expository written discourse. 
The reading comprehension tests (i.e., pre-test, post-test) designed by the researcher incorporated four major reading tasks: the wh-question task, the meaning-inferring task, the paraphrasing task, the summarizing task. Indeed, the fulfilment of these reading-based tasks entails a great amount of cognitive reasoning, critical thinking and metacognitive processing on the part of learners. The control as well as the treatment groups were assigned a reading test (i.e., narrative, expository) at both the pre-test and post-test levels. Thus, the assignment of each reading test (pre-test \& post-test) to the EFL participants belonging to the two groups (control \& treatment) took a two-hour period.

More explicitly, the pre- and post-tests were systematically given a score out of twenty (20) after being analyzed in terms of the correctness and accuracy of the responses relating to the stated text-related questions. Each set question is graded a scoring rubric. The comprehension questions task and the meaning-inferring task are assigned (7.50) and (4.00) respectively. As to the paraphrasing and summarizing tasks, they are granted (3.00) and (5.50) sequentially. Thus, the total score of the expository reading comprehension test is added up to that of the narrative reading comprehension test. Then, they are divided by two so as to get the final grade of the pre-test. This procedural criterion was applied to the post-test in a comparable way in an attempt to reach a reasonable, sound measurement.

In order to guarantee the reliability of the scoring procedure applied to the reading comprehension tests (pre-test \& post-test), it is worth noting that many significant modifications in terms of the scoring rubric were made to assure a certain kind of balance and objectivity in distributing and assigning the grades to the set questions pertaining to the reading comprehension texts included in the two tests. Hence, before starting the procedure of the data gathering, it was crucial to guarantee the feasibility and efficiency of the reading tests depended upon in the current study. This was executed through the process of "piloting" with the primary objective of detecting some prospective inadequacies and slight inconsistencies that can stand, at times, as a real impediment to the actual conduct of the research study. Further, for the purpose of ensuring the validity of the reading comprehension pre-test and post-tests, they were presented to some university instructors to gain highly constructive, informative feedback pertaining not only to the content of the reading tests and the adopted scoring method, but also to the relevance, accuracy and sequence of the comprehension questions used.

The obtained scores of the assigned reading comprehension tests (e.g., pre-test, post-test) were submitted to statistical analysis through the usage of both the Excel Software Program (version 2007) the SPSS Software Program (16.0). Indeed, both the paired-samples t-test and the independent samples t-test were implemented in an attempt to define and evince the means, standard deviations and mean differences among the target EFL groups (control \& experimental) at the pre-testing as well as the post-testing stage.

\section{Findings}

\subsection{EFL University Learners' Reading Achievement at Pre-testing}

Based on the reached outcomes of the pre-test, it is manifest that text typology (i.e., narrative, expository), as a prototypical embodiment of the discourse content, does not exert any marked influence on the target groups' reading performance gains. The pertinent findings are plainly presented in the following figure.

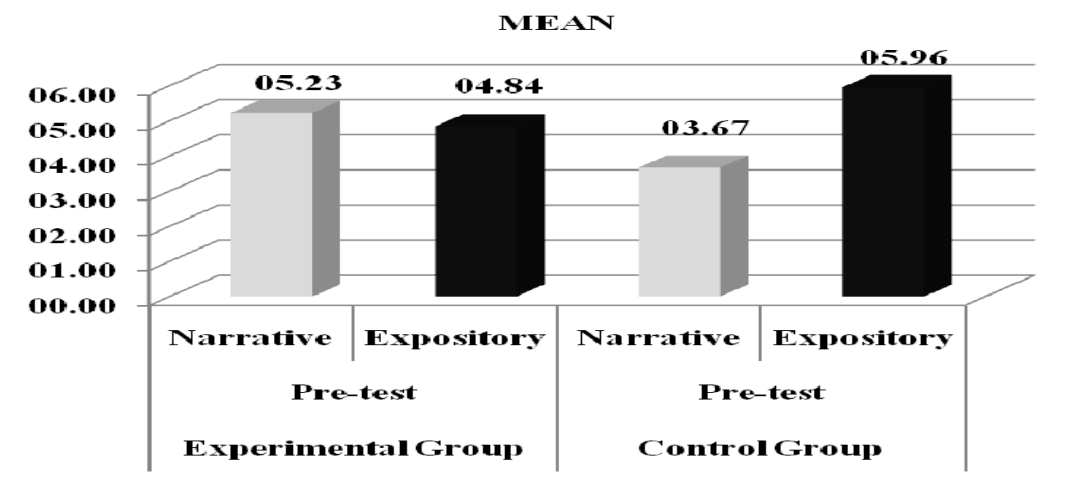

Figure 1. Experimental \& control groups' mean scores on the pre-test

As explicitly disclosed in figure 1, there seems to be discrepancy in the reading achievement gains between the narrative and expository reading comprehension tests among both the control and experimental groups at the 
pre-test level. In effect, the subjects in the control group scored relatively higher grades on the expository reading test than the narrative one. Contrariwise, the treatment subjects achieved higher gains on the narrative reading test compared to the expository one. This state of affairs can be ultimately accounted for by stating that processing either the narrative or the expository reading text, which were included in the pre-test, did not have any measurable effect on the learners' reading performance gains. Statistically speaking, the experimental group attained mean scores of (5.23) and (4.84) on the narrative and expository reading comprehension tests respectively. As to the control group, they reached a mean score of (3.67) for the narrative reading test and (5.96) for the expository reading test.

To back up the above-stated findings and to unveil the extent to which the typology of the written passage influences the EFL learners' reading gains, it was necessary that independent samples t-tests be performed. This presents a detailed account of the target subjects' reading performance as to each text type (e.g., narrative, expository). The results are clearly exhibited in the following two tables.

Table 1. EFL learners' achievement on the narrative reading test at pre-testing

Note. $\mathrm{P}<.05$.

\begin{tabular}{llllll}
\hline Groups & $\mathrm{N}$ & Mean & Mean dif. & t-value & Sig. (2-tailed) \\
\hline Control Group & 50 & 3.67 & -1.568 & -2.967 & \multirow{2}{*}{.004} \\
Experimental Group & 63 & 5.23 & & & \\
\hline
\end{tabular}

Table 2. EFL learners' achievement on the expository reading test at pre-testing

\begin{tabular}{llllll}
\hline Groups & $\mathrm{N}$ & Mean & Mean dif. & t-value & Sig. (2-tailed) \\
\hline Control Group & 50 & 5.96 & \multirow{2}{*}{1.110} & \multirow{2}{*}{1.826} & \multirow{2}{*}{0.71} \\
Experimental Group & 63 & 4.84 & & \\
\hline
\end{tabular}

As featured above, it is of note to claim that, whereas the experimental group outscored the control group at the level of the narrative reading test with a mean difference of $(-1.568)$, the reverse occurred when both groups were presented with the expository reading test with a plain difference in means of (1.110). In fact, the treatment group did not outperform its counterpart, the comparison group, on the expository reading test. This is testified to by the significance level which is lower than the set criterion (.05) for the narrative reading test (.004) and higher than the same criterion (.05) for the expository reading test (0.71). Therefore, text type does not seem to be an influential variable on the reading comprehension gains among EFL learners.

\subsection{EFL University Learners' Reading Achievement at Post-testing}

At the post-test stage, it was deducible that the reading performance of both participating groups (control \& experimental) was not genre-dependent. The results reached after scoring the narrative and expository reading post-tests of both EFL groups are presented in the figure that follows.

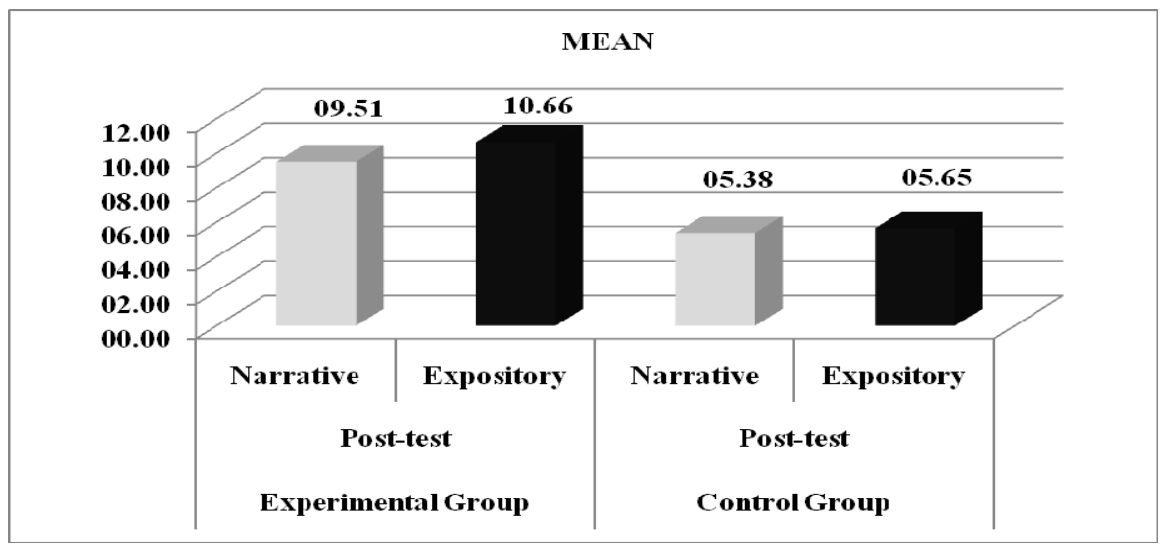

Figure 2. Experimental \& control groups' mean scores on the post-test 
The above-stated results seem to validate the postulate that text type is not a determining factor in the reading comprehension performance. This is plainly consistent with the findings of the pre-test. Though the control subjects did show some progress relating to the reading achievement gains of the narrative reading test $(\mathrm{M}=3.67$; $M=5.38)$, they did not advance in terms attaining significant gains on the expository reading test $(M=5.96$; $\mathrm{M}=5.65$ ) from the pre-test to the post-test stage. As for the experimental participants, they achieved significantly higher grades with means of (9.51) and (10.66) on the narrative and expository reading tests respectively. Actually, the fact that the experimental subjects attained a more significant mean score on the expository reading test than the narrative one at post-testing is in total opposition to their achievement at pre-testing in which they scored higher on the narrative reading test than the expository one (see Figures $1 \& 2$ ).

For providing somewhat accurate, confirmatory findings, the t-test, as an effective measuring statistical tool, was conducted on the obtained post-test data. Indeed, the two target groups (e.g., control, experimental) were compared in terms of the mean scores gained on the narrative as well as the expository reading test at post-testing. The two tables presented below manifest the relevant results.

Table 3. EFL learners' achievement on narrative reading test at post-testing

\begin{tabular}{llllll}
\hline Groups & $\mathrm{N}$ & Mean & Mean dif. & t-value & Sig. (2-tailed) \\
\hline Control Group & 50 & 5.38 & -4.135 & -6.748 & \multirow{2}{*}{.000} \\
Experimental Group & 63 & 9.51 & & & \\
\hline
\end{tabular}

Note. $\mathrm{P}<.05$.

Table 4. EFL Learners' achievement on expository reading test at post-testing

Note. $\mathrm{P}<.05$

\begin{tabular}{llllll}
\hline Groups & $\mathrm{N}$ & Mean & Mean dif. & t-value & Sig. (2-tailed) \\
\hline Control Group & 50 & 5.65 & -5.016 & -9.436 & .000 \\
Experimental Group & 63 & 10.66 & & & \\
\hline
\end{tabular}

The resultant outcomes gained by means of the independent samples t-test evince that the mean difference between the target groups (e.g., control, experimental) is positively significant both at the level of the narrative reading test (.000) and the expository one (.000). This indicates that the experimental treatment conducted over the course of the semester was a differentiating factor between the two groups where reading performance is concerned. Yet, given that the control group's mean score on the expository reading test (5.65) was not highly superior to that of the narrative reading test (5.38) and granted that the treatment group obtained slightly different means for the narrative (9.51) and the expository reading test (10.66), text type appears to have a non-significant effect on reading achievement.

All in all, the decline of the control group's mean score on the expository reading test from the pre- to the post-test level and the treatment group's higher performance gains on the narrative reading test at pre-testing and on the expository reading test at post-testing are clear evidence that text type is not an influencing variable on the reading achievement gains. This is highly suggestive that the typology of written discourse (i.e., narrative, expository) cannot immeasurably impact the EFL students' reading accomplishment scores in manifestly various dimensions.

\section{Discussion}

The present study revealed the extended extent to which text genre can starkly impact EFL learners' reading accomplishment. It also scrutinized whether strategy instruction has any marked effect on learners' attained scores on narrative and expository reading tests. These two primary objectives serve as the core foundation upon which this research is predicated.

It is important to state that the participating EFL learners' reading performance was rather different across the narrative and expository written tests at the pre-test and the post-test levels. Notably, a large number of the participants in the control group scored slightly better on the expository reading test than the narrative one at both the pre-test and post-test stages. Succinctly put, the EFL learners belonging to the control group tackled the expository reading test in a slightly efficient way. Nonetheless, across the pre-post-test continuum, their reading achievement as concerns the expository reading test decreased, whereas some mildly significant reading gains were achieved at the level of the narrative reading test. On the other hand, though the treatment group scored higher on the narrative than the expository reading test at the pre-test stage, their reading achievement was much 
greater on the expository reading test as compared to their reading gains of the narrative test at post-testing. Under this perspective, it is apparent that text genre was not an influencing variable on the reading gains in both tests (pre-test \& post-test). This is consistent with the outcomes of some research studies (e.g., Wolfe \& Mienko, 2007; Cervetti et al., 2009) backing up the view that text type does not predict differences in reading performance. This is, in a way, in accordance with the claim postulated in the first research hypothesis which states that text type does not have an effect on Moroccan EFL university learners' reading achievement gains.

Although most student-readers, from both control and experimental groups, did not measurably perform on the pre-test, their actual reading performance did not evince any significant difference at the level of text type. Yet, this plainly contradicts with previous research (Kucan \& Beck, 1996; Şahin, 2013) espousing that text type (i.e., narrative, expository) has an effect on reading test scores. The underlying evidence is that the impact of text genre (e.g., narrative, expository) on the learners' reading performance was not observable given the comparison drawn between the two groups before the strategy training intervention. Indeed, the scores obtained by the treatment group on the narrative reading pre-test markedly exceeded those attained by the controls. As to the expository reading pre-test, the reading gains realized by the control group were higher than those achieved by the treatment group. This is suggestive of the notion that the learners' reading achievement is not inextricably bound up with the type of written discourse.

Actually, despite the incremental increase in the intervention group's reading gains as regards the narrative and expository written texts at post-testing following the strategy instruction, the genre influence was not apparent. Particularly, the results of the post-test among the treatment group showed mild differences between the narrative and expository reading tests. For the sake of clarity, this group's performance on the expository reading test was moderately higher than their performance on the narrative reading test. This is contrary to the substantive reading outcomes achieved by the same group on the narrative rather than the expository reading test at the pre-testing level. This is, again, indicative of the premise that "genre effect" is not a crucial variable that characterizes and governs the outcomes of reading comprehension among the EFL learners. Thus, the view that EFL learners' reading gains are not significantly genre-dependent can be advocated.

The assumption that can be stated, in the light of what has been discussed thus far, is that text genre is unlikely to impact the reading test scores amongst EFL student-readers. In other terms, given that the strategy intervention is a significant contributor to augmenting the learners' reading achievement across the different written texts (e.g., narrative, expository), the element of genre cannot have any facilitative role in the text-processing performance (e.g., Wolfe \& Mienko, 2007; Cervetti et al., 2009). The variability at the level of scores gained on the two reading comprehension tests (e.g., narrative, expository) at post-testing cannot be attributable to the strategy-based intervention. Rather, the extensive instruction of the EFL learners in the deployment of reading "heuristics" can enhance the learners' capabilities to perform significantly better in both narrative and expository text processing. This confirms the second hypothesis of this research study that strategy instruction cannot be an influencing variable on learners' reading achievement with regards to text type (i.e., narrative, expository).

Accordingly, it can be held that the text genre is not a determining factor in comprehending textual information. The empirical findings yielded by this conducted case study are in support of previous research (e.g., Wolfe \& Mienko, 2007; Cervetti et al., 2009). Nonetheless, the study's findings contradict, in a way, some former empirical studies that advocate the increasing impact of text type on the learners' accomplishment in reading comprehension (Goelman, 1982; Geva \& Ryan, 1985; Kucan \& Beck, 1996). Clearly, the attained results of the current research refute, to some extent, the notion that the complexity of either the expository or the narrative reading test can be deemed an obvious factor behind the learners' attainment of lower or higher scores.

\section{Conclusion}

The current study placed a particular focus on the perceived influence of text type on EFL learners' reading accomplishment gains. It also investigated the extent to which strategy instruction can impact the narrative and expository reading test scores. In this vein, the reached findings did reveal that the impact of text genre on the reading comprehension scores is almost non-existent. Put differently, the component of text genre is not influential on the reading performance gains attained by the target EFL groups. This was shown by the pre-test as well as post-test results achieved by the two participating groups. Whereas the control group reflected somewhat better performance on the expository text than the narrative one, the experimental group evinced more increase in the reading achievement gains on the narrative text than the expository one at pre-testing.

More significantly, as the results of the comparison group testify, the decline in the mean score on the expository reading test from the pre- to the post-test session and the shift from a lower to a higher mean score on the narrative reading test across the pre-post-test sessions negate the possibility of "genre effect" on the reading 
performance. Thus, it can be concluded that the EFL learners' reading achievement is, to a greater extent, "immune" to the component of genre (e.g., narrative, expository).

Indeed, the variable of strategy instruction had an appreciable impact on learners' reading performance regardless of which text typology (i.e., narrative, expository) is tackled. In actuality, the improvement of the learners' reading gains across the pre-post test stages, especially among the experimental group, did not reveal any substantial effect of text type on the attained test scores. Though it is assumed that the learners' strategy use in processing the texts was somewhat specific to genre, their reading achievement was not genre-sensitive as indicated by the reached findings. Thus, it can be stated that the influence of the component of text type on using some reading techniques more frequently among EFL learners is apparent granted the salient features that characterize each text genre. However, learners' reading achievement scores, as evinced by the attained findings, were not governed by "genre-sensitivity".

\section{Implications}

It is noteworthy, apropos of the obtained results relevant to this research study, that the process of exposing EFL student-readers to differing text genres, namely narrative and expository written texts is an essential requirement in reading comprehension teaching at the university level. More clearly, it can be postulated that, only when EFL learners are presented with various typologies of written discourse can their analytical abilities, reasoning skills and processing techniques be further developed and raised to a fairly extended level. In recognizing the premise that the processing of differential text types does not have any impact on the EFL learners' reading achievement as shown by the current findings, it can be admitted that the interpretive analysis and effective synthesis of written texts that are of narrative as well as expository type can increase the EFL students' engagement in the cognitive act of reading and improve their "higher-order" thinking processes which constitute the cornerstone of the reading strategy application. Further, it is also implied that the assignment of somewhat challenging written texts (e.g., narrative, expository) to the EFL learners, namely at the first-semester stage, is of exceedingly primary importance to the development of a sturdy reading competence and the nurturing of the core analytical skills that enable an optimum synthesis/ analysis of academic textual discourse. It is true that, when EFL learners are assigned the written discourse (e.g., narrative, expository) that is characterized by easiness/ facility at the level of content, they will not foster an efficiency-oriented reading that involves critical thinking skills and metacognitive processes.

\section{Limitations \& Suggestions for Future Research}

It is worthy of claiming that any conducted research is not without limitations. The first one is incarnated in the fact that this case study was limited to the Faculty of Letters and Human Sciences in Rabat. Thus, it is critical that many Moroccan Faculties of Letters and Human Sciences and Higher Education Institutions be addressed and taken as representative case studies by future research with a view to obtaining adequacy in terms of the "representativity" of the Moroccan EFL student-readers. The second limitation is relatable to the premise that a large corpus of significant future research, which is longitudinal in nature, is in need of as concerns the perceived effect of text typology on the sampled EFL university learners' reading achievement. It is fairly suggested that prospective studies in the area of reading comprehension research be dependent on the assignment of a wide series of pre- and post-tests (e.g., narrative, expository) across the semesters. This proposed state of affairs can be a reasonably promising way to further substantiate that text type impact on the EFL learners' reading achievement is non-existent.

The third limitation is manifested in the gender variable which can be, to some extent, viewed as an intervening factor. Given that this research study was primarily concerned with testing the conceived impact of text type on the EFL learners' reading achievement, it did not take account of the reading performance gains (i.e., narrative, expository) obtained by the male subjects as opposed to the females belonging to the two EFL groups under investigation. In clearer terms, it can be estimated that the EFL female learners could perform significantly better on narrative and expository reading tests than the EFL male learners or vice versa. This investigation would have imparted insightfully rich data as to whether reading achievement on narrative and expository reading tests is somewhat "gender-specific". Thus, it can be posited that addressing the reading accomplishment by the EFL learners both before and after the instructional intervention from a gender perspective, which was beyond the scope of this research study, could be investigated and expatiated upon by further, future research.

\section{References}

Afflerbach, P. (1990). The influence of prior knowledge and text genre on readers' prediction strategies. Journal of Reading Behaviour, XXII(2), 131-148. http://dx.doi.org/10.1080/10862969009547700 
Alderson, J. C. (2000). Assessing Reading. Cambridge: Cambridge University Press. https://doi.org/10.1017/CBO9780511732935

Alderson, J. C., \& Urquhart, A. H. (1988). This test is unfair: I'm not an economist. In P. L. Carrell, J. Devine, \& D. E. Eskey (Eds.), Interactive Approaches to Second Language Reading (pp. 168-182). New York: Cambridge University Press. https://doi.org/10.1017/CBO9781139524513.018

Anderson, R. C. (1978). Schema-directed processes in language comprehension. In A. Lesgold, J. Pellegrino, S. Fokkema, \& R. Glaser (Eds), Cognitive Psychology and Instruction. New York: Plenum. https://doi.org/10.1007/978-1-4684-2535-2_8

Anderson, R. C., \& Pearson, P. D. (1988). A schema-theoretic view of basic processes in reading comprehension. In P. L. Carrell, J. Devine, \& D. E. Eskey (Eds.), Interactive Approaches to Second Language Reading (pp. 37-55). New York: Cambridge University Press. https://doi.org/10.1017/CBO9781139524513.007

Anderson, R. C., \& Pichert, J. W. (1978). Recall of previously unrecallable information following a shift in perspective. Journal of Verbal Learning and Verbal Behaviour, 17, 1-12. http://dx.doi.org/10.1016/S0022-5371(78)90485-1

Baretta, L., Tomitch, L. M. B., MacNair, N., Lim, V. K., \& Waldie, K. E. (2009). Inference making while reading narrative and expository texts: An ERP study. Psychology and Neuroscience, 2(2), 137-145. http://dx.doi.org/10.3922/j.psns.2009.2.005

Best, R. M., Floyd, R. G., \& McNamara, D. S. (2008). Differential competencies contributing to children's comprehension of narrative and expository texts. Reading Psychology, 29, 137-164. http://dx.doi.org/10.1080/02702710801963951

Carrell, P. L. (1984). Schema theory and ESL reading: Classroom implications and applications. The Modern Language Journal, 68(4), 332-343. http://dx.doi.org/10.1111/j.1540-4781.1984.tb02509

Carrell, P. L. (1987). Content and formal schemata in ESL reading. TESOL Quarterly, 21(3), 461-482. https://doi.org/10.2307/3586498

Casanave, C. P. (1988). Comprehension monitoring in ESL reading: A neglected essential. TESOL Quarterly, 22(2), 283-302. http://dx.doi.org/10.2307/3586937

Cervetti, G. N., Bravo, M. A., Hiebert, E. H., Pearson, P. D., \& Jaynes, C. A. (2009). Text genre and science content: Ease of reading, comprehension, and reader preference. Reading Psychology, 30(6), 487-511. http://dx.doi.org/10.1080/02702710902733550

Geva, E., \& Ryan, E. B. (1985). Use of conjunctions in expository texts by skilled and less skilled readers. Journal of Reading Behavior, 27, 331-346. http://dx.doi.org/ 10.1080/10862968509547549

Goelman, H. (1982). Selective attention in language comprehension: Children's processing of expository and narrative discourse. Discourse Processes, 5, 53-72. http://dx.doi.org/10.1080/01638538209544531

Harris, T., \& Hodges, R. (Eds.). (1995). The literacy dictionary: The vocabulary of reading and writing. Newark, DE: International Reading Association.

He, T. (2008). Reading for different goals: The interplay of EFL college students' multiple goals, reading strategy use and reading comprehension. Journal of Research in Reading, 31(2), 224-242. http://dx.doi.org/10.1111/j.1467-9817.2007.00355

Iwai, Y. (2016). The effect of explicit instruction on strategic reading in a literacy methods course. International Journal of Teaching and Learning in Higher Education, 28(1), 110-118.

Johnson, P. (1982). Effects on reading comprehension of building background knowledge. TESOL Quarterly, 16(4), 503-516. http://dx.doi.org/10.2307/3586468

Kucan, L., \& Beck, I. L. (1996). Four fourth graders thinking aloud: An investigation of genre effect. Journal of Literacy Research, 28(2), 255-287. http://dx.doi.org/10.1080/10862969609547921

Mokhtari, K., \& Reichard, C. A. (2002). Assessing students' metacognitive awareness of reading strategies. Journal of Educational Psychology, 94(2), 249-259. http://dx.doi.org/10.1037/0022-0663.94.2.249

Mokhtari, K., \& Sheory, R. (2002). Measuring ESL students' awareness of reading strategies. Journal of Developmental Education, 25(3), 2-10.

Pappas, C. C., \& Pettegrew, B. S. (1998). The role of genre in the psycholinguistic guessing game of reading. Language Arts, 75(1), 36-43. 
Rapp, D. N., \& Van den Broek, P. (2005). Dynamic text comprehension: An integrative view of reading. Current Directions in Psychological Science, 14(5), 276-279. http://dx.doi.org/10.1111/j.0963-7214.2005.00380.x

Rumelhart, D. E. (1984). Understanding understanding. In J. Flood (Ed.), Understanding Reading Comprehension (pp. 1-20). Newark, DE International Reading Association.

Şahin, A. (2013). The Effect of Text Types on Reading Comprehension. Mevlana International Journal of Education (MIJE), 3(2), 57-67. http://dx.doi.org/10.13054/mije.13.27.3.2

Smith, F. (1982). Understanding Reading: A Psycholinguistic Analysis of Reading and Learning to Read (3rd ed.). New York: CBS College Publishing.

Snow, C. (2002). Reading for Understanding: toward an RSD Program in Reading Comprehension. California: Rand Education.

Wolfe, M. B. W., \& Mienko, J. A. (2007). Learning and memory of factual content from narrative and expository $\begin{array}{llll}\text { text. British Journal of Educational Psychology, } & \text { 77(3), 541-564. }\end{array}$ http://dx.doi.org/10.1348/000709906X143902

Yoshida, M. (2012). The interplay of processing task, text type, and proficiency in L2 reading. Reading in a Foreign Language, 24(1), 1-29.

Zabrucky, K., \& Ratner, H. H. (1992). Effects of passage type on comprehension monitoring and recall in good and poor readers. Journal of Reading Literacy Research, XXIV(3), 373-391. http://dx.doi:10.1080/10862969209547782

Zhou, L., \& Siriyothin, P. (2011). Effects of text types on advanced EFL learners' reading comprehension. Journal of Language and Culture, 30(2), 45-66.

\section{Copyrights}

Copyright for this article is retained by the author, with first publication rights granted to the journal.

This is an open-access article distributed under the terms and conditions of the Creative Commons Attribution license (http://creativecommons.org/licenses/by/4.0/). 